\title{
The Gothenburg population-based glioblastoma research database: Methodological aspects and potential impact
}

\author{
Boglarka Fekete ${ }^{1,2}$, Katja Werlenius ${ }^{2,3}$, Helena Carén ${ }^{4}$, Anneli Ozanne ${ }^{5,6}$, Lars Rosengren ${ }^{1,6}$, Henrik Zetterberg $^{7-10}$, Magnus Tisell ${ }^{1,11}$, Anja \\ Smits $^{1,6,12}$, Fredrik Pontén ${ }^{13}$, Cecilia Lindskog ${ }^{13}$, Thomas Olsson Bontel1 ${ }^{14,15}$, Asgeir S. Jakola ${ }^{1,11}$, Bertil Rydenhag ${ }^{1,11^{*}}$ \\ ${ }^{1}$ Institute of Neuroscience and Physiology, Sahlgrenska Academy, Gothenburg, Sweden \\ ${ }^{2}$ Department of Oncology, Sahlgrenska University Hospital, Gothenburg, Sweden \\ ${ }^{3}$ Department of Oncology, Institute of Clinical Sciences, Sahlgrenska Academy, University of Gothenburg, Sweden \\ ${ }^{4}$ Department of Laboratory Medicine, Sahlgrenska Cancer Center, Institute of Biomedicine, Sahlgrenska Academy, University of Gothenburg, Sweden \\ ${ }^{5}$ Institute of Health and Care Sciences, Sahlgrenska Academy, University of Gothenburg, Sweden \\ ${ }^{6}$ Department of Neurology, Sahlgrenska University Hospital, Gothenburg, Sweden \\ ${ }^{7}$ Department of Psychiatry and Neurochemistry, Institute of Neuroscience and Physiology, Sahlgrenska Academy, University of Gothenburg, Mölndal, Sweden \\ ${ }^{8}$ Clinical Neurochemistry Laboratory, Sahlgrenska University Hospital, Mölndal, Sweden \\ ${ }^{9}$ Department of Neurodegenerative Disease, UCL Institute of Neurology, Queen Square, London, United Kingdom \\ ${ }^{10}$ UK Dementia Research Institute at UCL, London, United Kingdom \\ ${ }^{11}$ Department of Neurosurgery, Sahlgrenska University Hospital, Gothenburg, Sweden \\ ${ }^{12}$ Department of Neuroscience, Neurology, Uppsala University, Uppsala, Sweden \\ ${ }^{13}$ Department of Immunology, Genetics and Pathology, Rudbeck Laboratory, Uppsala University, Uppsala Sweden. \\ ${ }^{14}$ Department of Clinical Pathology and cytology, Sahlgrenska University Hospital, Gothenburg, Sweden \\ ${ }^{15}$ Department of Physiology, Institute of Neuroscience and Physiology, Sahlgrenska Academy, Gothenburg, Sweden
}

\begin{abstract}
Background: Glioblastoma Multiforme (GBM) is the most frequently encountered malignant primary brain tumour. Population-based studies of GBM are still scarce. The current paper describes the design of a prospective population-based multidisciplinary research effort on GBM.

Objective: To address the impact of a wide range of clinical parameters in relation to clinical outcome and survival in a population-based cohort of patients with GBM. Further, we aim to examine the role of established and novel biomarkers in tumour tissue and blood in relation to response to treatment and clinical outcome.

Methods: This is a single institution, population-based study with consecutive inclusion of patients based on a presumed diagnosis of GBM following radiological diagnostic work-up and discussion at a multidisciplinary tumour conference. Clinical parameters and treatment-related parameters at disease onset and during followup, and survival will be recorded. Health-related quality of life and emotional wellbeing for patients and their relatives will be assessed. Fresh-frozen and formalinfixed paraffin-embedded (FFPE) tumour tissue is stored in an associated tissue biobank. Tissue micro-arrays are generated from representative areas of FFPE. Blood samples at admission for surgery and during follow-up are taken and stored frozen.

Expected outcome: The study offers a multidisciplinary and translational approach to GBM research by linking a wide range of clinical parameters to biological parameters with high external validity. Thus, we expect to describe patterns of care and clinical course in a well-defined population-based cohort. Through a biomarker approach, we expect to 1) identify new biological subgroups of GBM,2) explore and validate established and novel biomarkers for response to therapy, 3) estimate the proportion of patients suitable for targeted ("druggable") therapy, and 4) explore and validate established and novel biomarkers for survival.
\end{abstract}

Abbreviations: GBM: Glioblastoma Multiforme; HRQoL: Health-related Quality of Life; SF-36: Short Form-36 Health Survey; HADS: Hospital Anxiety and Depression Scale.

\section{Introduction}

Glioblastoma (GBM), a frequently encountered tumour of the CNS, is the most malignant type of glioma with a median survival time of 6-12 months in population-based studies [1-4]. While current standard treatment has been shown to prolong survival, still less than $10 \%$ of patients survive for longer than 5 years $[5,6]$. The incidence of GBM is estimated to 4 per 100.000 individuals per year [7-10].
The burden of a disease and trends in incidence, prevalence and treatment of the specific condition over time are all important factors for

*Correspondence to: Bertil Rydenhag, Department of Neurosurgery, Sahlgrenska University Hospital, Blå Stråket 5, SE-41345 Gothenburg, Sweden, Tel: 46313429525; E-mail: Bertil.Rydenhag@neuro.gu.se

Key words: glioblastoma, quality of life, population-based cohort, tissue sampling, study protocol, tissue bank, biomarkers, survival, clinical outcome, prognosis, response to therapy

Received: September 08, 2019; Accepted: September 18, 2019; Published: September 23, 2019 
allocating optimal resources to a specific condition [11-13]. Although GBM is a relatively rare tumour, the short life expectancy associated with the disease makes it a public health problem. Further, when GBM affects a family member, it will affect the health of the closest family. It is therefore of outmost importance to widen current research efforts to enfold epidemiology, quality of life, clinical, biomarker and oncological research on a population basis. Population-based studies have high external validity, offer a clear picture of the burden of disease and will provide invaluable information on risk factors and trends over time [14]. Further, multiple analyses, from quality of life to clinical, molecular and cellular aspects, are ideally studied in a population-based setting.

Despite the extensive research efforts done in the field of GBM, many studies comprise of single centre investigations, with single surgeon experiences, and are ultimately subject to obscured selection and limited universality with low external validity. However, efforts towards clinical research networks with multicentre layout and development of tissue banks for translational research have also been made. The German Glioma Network is the result of such a collaborative effort covering multicentre population-based studies and encompassing both molecular genetics and clinical research [15].

At group level, several parameters have been shown to affect the survival of patients with GBM. Among these, the most important established factors are age $[1,2,9,16-19]$, performance status $[2,9,16$ $19]$, extent of resection $[1,9,17,18,20]$, location of the tumour $[16,19$ $21]$, multifocal location $[1,2,18]$, bilateral location $[1,9,19]$, type of oncological treatment [1,9,17-21], methylation status of the O-6methylguanine-DNA methyltransferase (MGMT) gene promoter [22-24], and isocitrate dehydrogenase (IDH) gene mutations [25,26]. However, the prognosis and response to the treatment at individual level is still difficult to predict. For the validation of established factors and the relative importance of each individual factor, a prospective study design is needed. Such a prospective study could ideally also pave the road for the detection of novel biomarkers through multi-analyses of collected bio samples.

The Gothenburg population based GBM research database uses a multidisciplinary approach enfolding several facets of GBM research at a population basis. Earlier we have investigated the clinical and treatment variables in GBM in a retrospective population-based setting [1]. The current clinical database and the associated biobank will address new questions that could not be answered in a retrospective setting. The actual paper presents a summary of this collaborative research effort and describes our study set-up in detail.

\section{Objectives}

The specific aims and objectives of the current study include:

- To investigate patterns of care and survival in relation to patientrelated, tumour-related and treatment-related parameters for GBM.

- To evaluate the role of established and potential novel diagnostic, predictive and prognostic biomarkers in tumour tissue and blood.

- To describe the subgroup of patients with radiological but no tissueverified diagnosis, such as elderly patients with poor performance status and severe co-morbidities.

- To evaluate the quality of life and emotional wellbeing of patients and their relatives over time with the aim to identify modifiable factors affecting these parameters.

\section{Patients and methods}

The Department of Neurosurgery in Gothenburg is the single neurosurgical centre in the Western region of Sweden with a referral base of about 2 million people. All patients with suspected primary brain tumours are referred to a multidisciplinary team (MDT) conference for diagnostic discussions and therapeutic decisions. The current study set-up comprises consecutive inclusion of patients with GBM diagnosis from November 2012 and onwards. To date, 558 patients have been enrolled in the study, we expect to include another 60 patients annually. The study protocol has been approved by the Regional Ethical Committee for Medical Research at Gothenburg University (Dnr. 17908, Dnr. 559-12, Dnr T505-18 and Dnr 604-12).

\section{Inclusion criteria in the surgical study}

Patients 18 years of age or older with a suspected diagnosis of a supratentorial GBM are consecutively included in the study. Decisions on diagnosis and study inclusion are made at MDT conferences, with MRI diagnostics as a cornerstone and evaluated by experienced neuroradiologists. Other members of the MDT are neurosurgeons, neuropathologist, oncologists, neurologists and tumour nurses. New cases are typically evaluated prior to and after surgery when histopathological tumour diagnosis becomes available. Patients with suspected GBM who are not selected for surgical intervention at the MDT conference, are included in the research database based on radiological diagnosis and followed for survival. Patients who have not been included following initial MDT conference but receive a histopathological GBM diagnosis are included in the study for further follow up.

\section{Exclusion criteria of the surgical study}

Exclusion criteria are age below 18 years or primarily suspicion of an alternative diagnosis. Patients for whom surgical intervention, i.e., biopsy or resection, is judged not possible or safe to perform, are included for clinical follow-up only. Common reasons for deferring surgical procedure are the general condition of the patient, the patient's own wish, or otherwise when high-risk procedures are not considered meaningful. Patients included based on MDT decision for whom the histopathological tumour diagnosis is not GBM, will be excluded.

\section{Description of the study}

\section{Clinical evaluation}

The study started in November 2012 with a consecutive inclusion of all GBM patients in our region. Prior to surgery, patients are informed by their treating neurosurgeon, and informed consent to participate in the study is obtained. All patients undergo a preoperative routine neurological examination and blood sampling for analysis of biomarkers in the blood.

After the surgical procedure, a postoperative MRI is performed within 72 hours to assess the extent of the surgical resection. Radical resection of a tumour is considered to be complete resection of the enhancing tumour (CRET) [27] with no contrast enhancement left. All other extent of resection is considered partial. In addition, volumetric approaches using dedicated software and evaluation of tumour remnant in a volumetric manner are conducted for specific projects when considered appropriate. The biopsy procedure could be open via craniotomy or using any kind of stereotaxy (frame-based or frameless). Neurologic examination is performed following MRI and prior to discharge from the neurosurgical ward. All patients are followed up in connection with oncological treatment. Overall survival is defined as 
the time interval between the day of the surgery and the date of death or of the last follow-up.

\section{Established Clinical and Molecular Markers}

The following basic clinical data and demographics for survival are collected: age at surgery, gender, location of tumour (multifocal, bilateral), extent of resection, comorbidity, WHO performance status [28], neurological deficits, initial symptomatology (reversible by corticosteroids or not), as well as comorbidity. In addition, established molecular markers for GBM (IDH genotype, MGMT methylation status) are analysed (see Tissue Handling).

\section{Blood Biomarkers}

At the admission to the neurosurgical department, blood samples are taken for analysis of biomarkers, such as glial fibrillary acidic protein (GFAp), neurofilament light protein (NfL), phosphorylated neurofilament heavy ( $\mathrm{pNfH}$ ) and tau (a microtubule-associated protein). GFAp is the main intermediate filament protein in astrocytes [29]. GFAp in serum has been shown to correlate to the size of GBM [30] but is so far not indicated as a prognostic biomarker [30-32]. The neurofilament proteins are the main structural components of axons; particularly large myelinated axons [33]. These biomarkers have yet not been studied in blood in connection to cerebral tumours. Tau is a microtubule-associated protein, mainly located in unmyelinated axons with the main function of stabilizing the axonal cytoskeleton [34]. Tau has so far not been analysed in blood in connection with GBM. However, serum tau has been associated with poor outcome and presence of brain metastases in breast cancer [35]. Aliquots of serum and plasma are frozen for later analysis and correlated to the clinical course and survival. Follow up blood samples may be taken throughout the clinical course. In addition, an appropriate control group will be analysed when considered relevant. Finally, potential new markers may also be analysed. State-of-the art ultrasensitive immunoassays, including Single molecule array (Simoa) and Single molecule counting (SMC) will be used for the measurements.

\section{Tissue handling in the pathology department}

Tumour tissue is fixed with $4 \%$ formaldehyde, dehydrated and embedded in paraffin wax. A clinical histopathologyworkup is performed by a specialist in neuropathology according to WHO 2007 [36] and WHO $2016[37,38]$ classification. The workup is based on routine stains and ancillary techniques, such as special stains, immunohistochemistry and next generation sequencing. Fluorescence in situ hybridization is sometimes used, mostly for exclusion of differential diagnoses. For routine stains, sections $(4 \mu \mathrm{m})$ are cut using a microtome (RM2255 or RM2165 Leica), placed in heated water bath to expand and mounted on SuperFrost ${ }^{\mathrm{sc}}$ Adhesion slides (Thermo Scientific). The sections are dried in a heating cabinet for 15 to 30 minutes prior to deparaffinization and staining with Mayer's haematoxylin and eosin (H\&E; Histolab, Sweden). For immunohistochemistry, tumour tissue is stained using a DAKO Autostainer and Envision FLEX+ detection system. Briefly, deparaffinized sections are subjected to antigen retrieval by boiling at high $\mathrm{pH}$ for $20 \mathrm{~min}$, followed by blocking with hydrogen peroxide and incubation with primary antibodies against various antibodies. The detection system amplifies the primary antibody signal and the reaction is visualized by $\mathrm{DAB}+$ chromogen. IDH mutation is analysed with immunohistochemistry with antibodies detecting IDH1 R132H point mutation (Dianova DIA-H09) or next generation sequencing including the most common IDH1 and IDH2 point mutations (Ion AmpliSeq CancerHotspot v2 Panel, ThermoFisher). For analysis of MGMT-promoter methylation levels, the mean value of methylation levels of four analysed CpG-sites is measured. DNA is extracted (Qiagen QIAamp DNA FFPE-kit) and bisulfite converted (EpiTect Plus FFPE Bisulfite Kit, Qiagen). MGMT promoter methylation levels are then analysed with pytosequencing (Qiagen Therascreen MGMT Pyro Kit). The outcomes are interpreted according to Dunn et al. [39] and Reifenberger et al. [40], and according to Quillien et al. [41].

\section{Antibody-based proteomics}

Antibody-based proteomics provides a strategy for the systematic generation and usage of specific antibodies to explore the proteome [42]. The Swedish Human Protein Atlas (HPA) program has been set up to generate a comprehensive map of protein expression patterns in human tissues and cells [43]. The expression of over 24.000 antibodies corresponding to 16.975 protein-encoding genes in the human genome have so far been successfully characterized and published as large open access knowledge-based data on the HPA portal (www.proteinatlas. org) [43]. This multi-disciplinary research program combines largescale generation of antibodies with protein profiling in human tissues and cells, using high-throughput immunohistochemistry on tissue microarrays (TMAs). Paraffin blocks derived from GBM with representative tumour areas are used for production of TMAs. TMAs are generated as previously described [44], including two tissue cores from each donor block.

\section{Tissue epigenetics}

The 2016 WHO classification of brain tumours is based on histopathological criteria in combination with molecular markers [37, 38]. DNA methylation-based classifiers have been shown to accurately classify and stratify patients into subgroups with distinct survival times [45-48] and are hence considered for clinical diagnostics, and already used for this purpose [49]. Samples of the tumour extirpated are fresh-frozen in case enough material is available. DNA is extracted from samples with $>70 \%$ tumour cell content. It has been demonstrated that fresh frozen as well as formalin-fixed paraffin-embedded tissue is suitable for DNA methylation-based classification [50], and formalin-fixed paraffin-embedded tissue is used when fresh frozen is not available. DNA methylation-based classification can be used to accurately assign a correct diagnosis ( $~ 15 \%$ of brain tumours have been shown to be incorrectly diagnosed using standard methods [51]), to generate chromosomal copy number profiles and for independent assessment of MGMT methylation status [52,53]. The possibility to profile DNA methylation will therefore enable state-of-the-art analyses of the collected tumour tissue.

\section{Quality of Life and emotional wellbeing}

Short form health survey (SF-36) is a generic questionnaire about health status and it is one of the most widely used measures of healthrelated quality of life (HRQoL) in patient studies. The instrument has been translated and standardized after Swedish standards with good validity and reliability [54-56]. The subscales achieve representation of health concepts from a multi-dimensional perspective. The domains range from 0 to 100 (worst possible health state to best possible health state) [56] and is divided into two dimensions of health; physical component summary and mental component summary [54]. The Hospital Anxiety and Depression Scale (HADS) is a validated selfassessment scale with 14 items, divided in two subscales including the person's own experience of anxiety and depression. Items range from 0 to 3 on a four-point Likert scale. The sums range from 0 to 21 . Seven points or lower indicate absence of significant levels of anxiety or depression, scores between 8 and 10 indicate doubtful cases, and scores over 11 indicate definite cases of anxiety or depression [57]. 
Patients and relatives estimate their HRQoL by SF-36 and emotional wellbeing by HADS preoperatively as well as at 3 weeks, 12 weeks, 6 months, 1 year, 1.5 year and 2 year postoperatively or until they are no longer able to participate. In addition, open-ended questions regarding experiences of treatment, information and support will be included.

\section{Statistical analyses for the QoL part}

Descriptive statistics such as median with range and mean with standard deviation will be used to present data. Paired comparisons between patients and relatives will be analysed by Wilcoxon signedrank test and differences between groups (gender) by the MannWhitney U test. Multivariate linear regression will be used for SF-36 and HADS for patients as well as relatives. Longitudinal analyses shall also be performed.

\section{Qualitative analysis and interview study}

SF36 and the HADS will be completed by patients and their relatives, together with open-ended questions regarding experienced information and support over time. The data will be analysed by qualitative content analysis, focusing on the manifest content on a descriptive level close to the text [58], systematically analysing written or verbal communication [59]. Patients and their relatives will be interviewed from a semi-structured guide, using maximum variation sampling [60]. Factors relevant are age, gender, type of resection/biopsy, time from surgery, and physical and cognitive function. The method is hermeneutic [61].

\section{Statistical analyses}

Statistical analysis will be performed in collaboration with a specialised statistical consult group. For categorical variables, numbers and percentages are presented. For continuous variables, mean, standard deviation, median, minimum, and maximum are used. Time-to-death analyses may be done by Poisson regression models for time-varying data with time post-surgery divided into intervals: start - 1 year, $1-3.5$ years, and > 3.5 years in the study. This way, the effect of time itself is investigated as one of the risks for death.

\section{Discussion}

We describe a single-centre, prospective, population-based and observational study including a minimum of 60 GBM patients annually in a prospective consecutive setting. In this setting, we will evaluate the impact of traditional clinical factors as well as the putative role of biomarkers in tumour tissue and blood. The study setting offers a possibility for translational research linking basic tumour research (e.g., tumour markers and biomarkers in blood) to clinical parameters, such as survival time and response to treatment. The multidisciplinary approach allows the evaluation of multiple study parameters affecting clinical outcome and survival in a well-defined cohort of patients.

GBM cause huge physical and emotional stress for the patient $[62,63]$, and will probably also affect the life among relatives. However, few studies so far have examined the HRQoL and emotional wellbeing of patients and their relatives over time, in relation to each other, or in relation to clinical parameters. These important aspects are to be studied in this project and used to design a support model to improve the care not only for the patients but also for their families.

\section{Expected outcome}

We expect to find clinical predictors for long-term and short-term survival that can be used to guide individual treatment decisions. We may also identify novel prognostic and predictive biomarkers in blood samples and tumour tissue. For example, blood-based biomarkers may be able to predict recurrence of tumour at an early stage. Further knowledge on the HRQoL and emotional wellbeing of patients and their relatives will be used to improve future care.

\section{Strengths and limitations}

The population-based prospective design with high external validity is one of the major strengths. As such, the opportunities for translational and multidisciplinary research are abundant, due to well-grounded collaborations. Missing cases, including patients who undergo emergency surgery or are too ill to give informed consent constitute one of the limitations, but our experience so far is that these cases are few.

\section{Conflicts of interest}

HZ - HZ has served at scientific advisory boards for Roche Diagnostics, Wave, Samumed and $\operatorname{CogRx}$, has given lectures in symposia sponsored by Biogen and Alzecure, and is a co-founder of Brain Biomarker Solutions in Gothenburg AB, a GU Ventures-based platform company at the University of Gothenburg (all unrelated to the submitted work).

\section{Acknowledgments}

We acknowledge the important work of our research assistant and nurses; Gerd Ekstedt, Ünzüle Yildiz, Anneli Johansson and many more.

\section{Funding}

This study is financed by grants from the Swedish state under the agreement between the Swedish government and the county councils, the ALF-agreements: (\#ALFGBG-716671, Jakola; \#ALFGBG-717021, Smits, \#ALFGBG-720931, Zetterberg), Health Medical Care Committee at Västra Götaland (Regional FoU-support; VGFOUREG-750851, Rydenhag), AFA Research Foundation (Rydenhag), Margaretahemmet foundation and the Gothenburg Foundation for Neurological Research (Fekete), The Gothenburg Medical Society (Olsson Bontell). Zetterberg is a Wallenberg Academy Fellow supported by grants from the Swedish Research Council (\#2018-02532) and the European Research Council (\#681712).

\section{References}

1. Fekete B, Werlenius K, Örndal C, Rydenhag B (2016) Prognostic factors for glioblastoma patients--a clinical population-based study. Acta Neurol Scand 133: 434441. [Crossref]

2. Hansen S, Rasmussen BK, Laursen RJ, Kosteljanetz M, Schultz H, et al. (2018) Treatment and survival of glioblastoma patients in Denmark: The Danish NeuroOncology Registry 2009-2014. J Neurooncol 139: 479-89. [Crossref]

3. Ronning PA, Helseth E, Meling TR, Johannesen TB (2012) A population-based study on the effect of temozolomide in the treatment of glioblastoma multiforme. Neuro Oncol 14: 1178-84. [Crossref]

4. Bruhn H, Strandeus M, Milos P, Hallbeck M, Vrethem M, et al. (2018) Improved survival of Swedish glioblastoma patients treated according to Stupp. Acta Neurol Scand 138: 332-337. [Crossref]

5. Stupp R, Hegi ME, Mason WP, van den Bent MJ, Taphoorn MJ, et al. (2009) Effects of radiotherapy with concomitant and adjuvant temozolomide versus radiotherapy alone on survival in glioblastoma in a randomised phase III study: 5-year analysis of the EORTC-NCIC trial. Lancet Oncol 10: 459-466. [Crossref]

6. Stupp R, Mason WP, van den Bent MJ, Weller M, Fisher B, et al. (2005) Radiotherapy plus concomitant and adjuvant temozolomide for glioblastoma. N Engl J Med 352: 987996. [Crossref]

7. Brodbelt A, Greenberg D, Winters T, Williams M, Vernon S, et al. (2015) Glioblastoma in England: 2007-2011. Eur J Cancer 51: 533-542. [Crossref] 
8. Li K1, Lu D2, Guo Y1, Wang C1, Liu X1, et al. (2018) Trends and patterns of incidence of diffuse glioma in adults in the United States, 1973-2014. Cancer Med 7: 5281-5290. [Crossref]

9. Helseth R, Helseth E, Johannesen TB, Langberg CW, Lote K, et al. (2010) Overall survival, prognostic factors, and repeated surgery in a consecutive series of 516 patients with glioblastoma multiforme. Acta Neurol Scand 122: 159-167. [Crossref]

10. Lorimer CF, Hanna C, Saran F, Chalmers A, Brock J (2017) Challenges to Treating Older Glioblastoma Patients: The Influence of Clinical and Tumour Characteristics on Survival Outcomes. Clin Oncol (R Coll Radiol) 29: 739-47. [Crossref]

11. Edelstein K, Coate L, Massey C, Jewitt NC, Mason WP, et al. (2016) Illness intrusiveness and subjective well-being in patients with glioblastoma. $J$ Neurooncol 126: 127-135. [Crossref]

12. Rooney AG, Carson A, Grant R (2011) Depression in cerebral glioma patients: a systematic review of observational studies. J Natl Cancer Inst 103: 61-76. [Crossref]

13. Roth P, Gramatzki D, Weller M (2017) Management of Elderly Patients with Glioblastoma. Curr Neurol Neurosci Rep 17: 35. [Crossref]

14. Szklo M (1998) Population-based cohort studies. Epidemiol Rev 20: 81-90. [Crossref]

15. Weller M, Felsberg J, Hartmann C, Berger H, Steinbach JP, et al. (2009) Molecular predictors of progression-free and overall survival in patients with newly diagnosed glioblastoma: a prospective translational study of the German Glioma Network. J Clin Oncol 27: 5743-5750. [Crossref]

16. Chaichana K, Parker S, Olivi A, Quinones-Hinojosa A (2010) A proposed classification system that projects outcomes based on preoperative variables for adult patients with glioblastoma multiforme. J Neurosurg 112: 997-1004. [Crossref]

17. Scoccianti S, Magrini SM, Ricardi U, Detti B, Buglione M, et al. (2010) Patterns of care and survival in a retrospective analysis of 1059 patients with glioblastoma multiforme treated between 2002 and 2007: a multicenter study by the Central Nervous System Study Group of Airo (italian Association of Radiation Oncology). Neurosurgery 67: 446-458. [Crossref]

18. Stark AM van de Bergh J, Hedderich J, Mehdorn HM, Nabavi A (2012) Glioblastoma: clinical characteristics, prognostic factors and survival in 492 patients. Clin Neurol Neurosurg 114: 840-845. [Crossref]

19. Tait MJ, Petrik V, Loosemore A, Bell BA, Papadopoulos MC (2007) Survival of patients with glioblastoma multiforme has not improved between 1993 and 2004: analysis of 625 cases. Br J Neurosurg 21: 496-500. [Crossref]

20. Mineo JF, Bordron A, Baroncini M, Ramirez C, Maurage CA, et al. (2007) Prognosis factors of survival time in patients with glioblastoma multiforme: a multivariate analysis of 340 patients. Acta Neurochir (Wien) 149: 245-252. [Crossref]

21. Li SW, Qiu XG, Chen BS, Zhang W, Ren H, et al. (2009) Prognostic factors influencing clinical outcomes of glioblastoma multiforme. Chin Med J (Engl) 122: 1245-1249. [Crossref]

22. Hegi ME, Diserens AC, Gorlia T, Hamou MF, de Tribolet N, et al. (2005) MGMT gene silencing and benefit from temozolomide in glioblastoma. $N$ Engl J Med 352: 997-1003. [Crossref]

23. Malmstrom A, Gronberg BH, Marosi C, Stupp R, Frappaz D, et al. (2012) Temozolomide versus standard 6-week radiotherapy versus hypofractionated radiotherapy in patients older than 60 years with glioblastoma: the Nordic randomised, phase 3 trial. Lancet Oncol 13: 916-926. [Crossref]

24. Stummer W, Meinel T, Ewelt C, Martus P, Jakobs O, et al. (2012) Prospective cohort study of radiotherapy with concomitant and adjuvant temozolomide chemotherapy for glioblastoma patients with no or minimal residual enhancing tumor load after surgery. $J$ Neurooncol 108: 89-97. [Crossref]

25. Szopa W, Burley TA, Kramer-Marek G, Kaspera W (2017) Diagnostic and Therapeutic Biomarkers in Glioblastoma: Current Status and Future Perspectives. Biomed Res Int 2017: 8013575. [Crossref]

26. Wang PF, Song HW, Cai HQ, Kong LW, Yao K et al. (2017) Preoperative inflammation markers and IDH mutation status predict glioblastoma patient survival. Oncotarget 8 : 50117- 50123. [Crossref]

27. Kreth FW, Thon N, Simon M, Westphal M, Schackert G, et al. (2013) Gross total but not incomplete resection of glioblastoma prolongs survival in the era of radiochemotherapy. Ann Oncol 24: 3117-3123. [Crossref]

28. Oken MM, Creech RH, Tormey DC, Horton J, Davis TE, et al. (1982) Toxicity and response criteria of the Eastern Cooperative Oncology Group. Am J Clin Oncol 5: 649655. [Crossref]
29. Brenner M (2014) Role of GFAP in CNS injuries. Neurosci Lett 565: 7-13. [Crossref]

30. Brommeland T, Rosengren L, Fridlund S, Hennig R, Isaksen V (2007) Serum levels of glial fibrillary acidic protein correlate to tumour volume of high-grade gliomas. Acta Neurol Scand 116: 380-384. [Crossref]

31. Tichy J, Spechtmeyer S, Mittelbronn M, Hattingen E, Rieger J, et al. (2016) Prospective evaluation of serum glial fibrillary acidic protein (GFAP) as a diagnostic marker for glioblastoma. J Neurooncol 126: 361-369. [Crossref]

32. Vietheer JM, Rieger J, Wagner M, Senft C, et al. (2017) Serum concentrations of glia fibrillary acidic protein (GFAP) do not indicate tumor recurrence in patients with glioblastoma. J Neurooncol 135: 193-199. [Crossref]

33. Pujol-Calderón F, Portelius E, Zetterberg H, Blennow K, Rosengren LE, et al. (2019) Neurofilament changes in serum and cerebrospinal fluid after acute ischemic stroke. Neurosci Lett 698: 58-63. [Crossref]

34. Feinstein SC, Wilson L (2005) Inability of tau to properly regulate neuronal microtubule dynamics: a loss-of-function mechanism by which tau might mediate neuronal cell death. Biochim Biophys Acta 1739: 268-279. [Crossref]

35. Darlix A, Hirtz C, Thezenas S, Maceski A, Gabelle A, et al. (2019) The prognostic value of the Tau protein serum level in metastatic breast cancer patients and its correlation with brain metastases. BMC Cancer 19: 110. [Crossref]

36. Louis DN, Wiestler OD, Cavene WK. World Health Organization histological classification of tumours of the central nervous system. Lyon: international Agency for Research on Cancer; 2007.

37. Louis DN, Wiestler OD, Cavene WK. World Health Organization histological classification of tumours of the central nervous system. Lyon: international Agency for Research on Cancer; 2016.

38. Louis DN, Perry A, Reifenberger G, von Deimling A, Figarella-Branger D, et al. (2016) The 2016 World Health Organization Classification of Tumors of the Central Nervous System: a summary. Acta Neuropathol 131: 803-820. [Crossref]

39. Dunn J, Baborie A, Alam F, Joyce K, Moxham M, et al. (2009) Extent of MGMT promoter methylation correlates with outcome in glioblastomas given temozolomide and radiotherapy. Br J Cancer 101: 124-131. [Crossref]

40. Reifenberger G, Hentschel B, Felsberg J, Schackert G, Simon M, et al. (2012) Predictive impact of MGMT promoter methylation in glioblastoma of the elderly. Int $J$ Cancer 131: 1342-1350. [Crossref]

41. Quillien V, Lavenu A, Ducray F, Joly MO, Chinot O, et al. (2016) Validation of the high-performance of pyrosequencing for clinical MGMT testing on a cohort of glioblastoma patients from a prospective dedicated multicentric trial. Oncotarget 7 : 61916- 61929. [Crossref]

42. Uhlen M, Ponten F (2005) Antibody-based proteomics for human tissue profiling. Mol Cell Proteomics 4: 384-393. [Crossref]

43. Uhlén M, Fagerberg L, Hallström BM, Lindskog C, Oksvold P, et al. (2015) Proteomics. Tissue-based map of the human proteome. Science 347: 1260419. [Crossref]

44. Kampf C, Olsson I, Ryberg U, Sjostedt E, Ponten F (2012) Production of tissue microarrays, immunohistochemistry staining and digitalization within the human protein atlas. J Vis Exp 63. [Crossref]

45. Capper D, Jones DTW, Sill M, Hovestadt V, Schrimpf D, et al. (2018) DNA methylation-based classification of central nervous system tumours. Nature 555: 469474. [Crossref]

46. Danielsson A, Nemes S, Tisell M, Lannering B, Nordborg C, et al. (2015) MethPed: DNA methylation classifier tool for the identification of pediatric brain tumor subtypes. Clin Epigenetics 7: 62. [Crossref]

47. Sturm D, Witt H, Hovestadt V, Khuong-Quang DA, Jones DT, et al. (2012) Hotspot mutations in $\mathrm{H} 3 \mathrm{~F} 3 \mathrm{~A}$ and IDH1 define distinct epigenetic and biological subgroups of glioblastoma. Cancer Cell 22: 425-437. [Crossref]

48. Taylor MD, Northcott PA, Korshunov A, Remke M, Cho YJ, et al. (2012) Molecular subgroups of medulloblastoma: the current consensus. Acta Neuropathol 123: 465-472. [Crossref]

49. Jaunmuktane Z, Capper D, Jones DTW, Schrimpf D, Sill M, et al. (2019) Methylation array profiling of adult brain tumours: diagnostic outcomes in a large, single centre. Acta Neuropathol Commun 7: 24. [Crossref] 
50. Kling T, Wenger A, Beck S, Caren H (2017) Validation of the MethylationEPIC BeadChip for fresh-frozen and formalin-fixed paraffin-embedded tumours. Clin Epigenetics 9: 33. [Crossref]

51. Capper D, Stichel D, Sahm F, Jones DTW, Schrimpf D, et al. (2018) Practical implementation of DNA methylation and copy-number-based CNS tumor diagnostics: the Heidelberg experience. Acta Neuropathol 136: 181-210. [Crossref]

52. Bady P, Delorenzi M,Hegi ME (2016) Sensitivity Analysis of the MGMT-STP27 Model and Impact of Genetic and Epigenetic Context to Predict the MGMT Methylation Status in Gliomas and Other Tumors. J Mol Diagn 18: 350-361. [Crossref]

53. Hovestadt V, Zapatka M (2019) Enhanced copy-number variation analysis using illumina DNA methylation arrays. R package version 0.99.4. Bioconductor. Available from: http://www.bioconductor.org/packages/release/bioc/html/conumee.html.

54. Persson LO, Karlsson J, Bengtsson C, Steen B, Sullivan M (1998) The Swedish SF-36 Health Survey II. Evaluation of clinical validity: results from population studies of elderly and women in Gothenborg. J Clin Epidemiol 51: 1095-1103. [Crossref]

55. Sullivan M, Karlsson J (1998) The Swedish SF-36 Health Survey III. Evaluation of criterion-based validity: results from normative population. J Clin Epidemiol 51: 11051113. [Crossref]
56. Sullivan M, Karlsson J, Ware JE Jr (1995) The Swedish SF-36 Health Survey--I. Evaluation of data quality, scaling assumptions, reliability and construct validity across general populations in Sweden. Soc Sci Med 41: 1349-1358. [Crossref]

57. Zigmond AS, Snaith RP (1983) The hospital anxiety and depression scale. Acta Psychiatr Scand 67: 361-370. [Crossref]

58. Graneheim UH, Lundman B (2004) Qualitative content analysis in nursing research: concepts, procedures and measures to achieve trustworthiness. Nurse Educ Today 24: 105-112. [Crossref]

59. Krippendorff K (2013) Content analysis: an introduction to its methodology. Thousand Oaks, CA: SAGE

60. Patton MQ (2015) Qualitative research \& evaluation methods: Integrating theory and practice: Thousand Oaks, California: SAGE Publicaionts Inc; 2015

61. Gadamer H-G (2004) Truth and method, 2nd rev: United Kingdom: Continuum.

62. Sizoo EM, Dirven L, Reijneveld JC, Postma TJ, Heimans JJ, et al. (2014) Measuring health-related quality of life in high-grade glioma patients at the end of life using a proxy-reported retrospective questionnaire. J Neurooncol 116: 283-290. [Crossref]

63. Walbert T, Chasteen K (2015) Palliative and supportive care for glioma patients. Cancer Treat Res 163: 171-184. [Crossref]

Copyright: $\odot 2019$ Fekete B. This is an open-access article distributed under the terms of the Creative Commons Attribution License, which permits unrestricted use, distribution, and reproduction in any medium, provided the original author and source are credited. 